\title{
Efeito da Cor do Ambiente sobre o Estresse Social em Tilápias do Nilo (Oreochromis niloticus) ${ }^{1}$ \\ Giovana Krempel Fonseca Merighe², Elyara Maria Pereira-da-Silva ${ }^{3}$, João Alberto Negrão ${ }^{3}$, Sandra Ribeiro 4
}

\begin{abstract}
RESUMO - Estudaram-se as respostas comportamentais e fisiológicas de juvenis de tilápia do Nilo (Oreochromis niloticus) submetidos a diferentes cores de ambientes e situações sociais. Os animais foram mantidos isolados em aquários recobertos com papelcartão colorido, compondo cinco tratamentos (preto, verde, marrom, azul e branco).Utilizando-se filmagens semanais realizadas em etapas distintas e alternadas (isolamento e presença de um espelho), registraram-se os seguintes parâmetros: distribuição na coluna d’água, coloração, atividade locomotora, confrontos agonísticos, posição da nadadeira dorsal e postura. Para quantificação dos níveis plasmáticos de glicose, triglicerídeos, proteínas totais e cortisol, coletaram-se amostras de sangue após cada filmagem. As médias obtidas foram analisadas estatisticamente pelo método não-paramétrico de Kruskal-Wallis. Os peixes mantidos nos ambientes preto e verde apresentaram baixas freqüências de confrontos agonísticos, enquanto aqueles mantidos no ambiente branco, altas freqüências, porém com redução do padrão ameaça e não alterando sua locomoção. Animais submetidos às cores marrom e azul apresentaram as mais altas freqüências de comportamentos agonísticos e maior atividade locomotora. Os peixes permaneceram em todos os tratamentos com a coloração clara, ocupando, com maior freqüência, a região inferior da coluna d’água. Não foram observadas diferenças significativas para as concentrações de glicose, triglicerídeos e proteínas totais entre os tratamentos, porém obteve-se elevado nível de cortisol para os animais mantidos nos ambientes azul e marrom, quando submetidos à reflexão da própria imagem em espelho. Estes resultados mostraram que existe influência da cor do ambiente sobre o estresse social, em particular nas interações agonísticas entre coespecíficos e na concentração do hormônio cortisol. Concluiu-se que as cores verde e preta são recomendadas à manutenção da espécie, por amenizarem as interações agonísticas e o estresse, enquanto a marrom e azul devem ser evitadas por estimularem estas respostas.
\end{abstract}

Palavras-chave: agressividade, comportamento, cor do ambiente, estresse social, metabolismo, Oreochromis niloticus

\section{Effect of Background Color on the Social Stress of Nile Tilapia (Oreochromis niloticus)}

\begin{abstract}
It was studied the behavior and physiologic answers of juvenile of Nile tilapia, Oreochromis niloticus, submitted the different backgrounds colors and social situations. The animals were maintained isolated in fishbowls covered with colored paper-card, composing five treatments (black, green, brown, blue and white). Through weekly filmings and in different and alternate stages (isolation and presence of a mirror), it enrolled the following parameters: distribution in the column of water, coloration, motility, agonistic behaviors, position of the dorsal fin and posture. For quantification of the glucose, triglycerides, total proteins and cortisol levels, were collected samples of blood after each filming. The obtained averages were analyzed statistically through the no-parametric Kruskal-Wallis method. The fish maintained in the black and green background presented low frequencies of agonistic behaviors, while those maintained in the white background, high frequencies, even so with low numbers of the alert pattern and not altering its motility. Animals submitted to the brown and blue colors presented the highest frequencies of agonistic behaviors, and larger motility. The fish stayed in all the treatments with the clear coloration, occupying, with larger frequency, the bottom of the column of water. Significant differences were not observed for the glucose, triglycerides and total proteins concentrations among the treatments, even so it was obtained a high level of cortisol for the animals maintained in the blue and brown backgrounds when submitted to the reflection of the own image in mirror. These results showed that there is influence of the background color on the social stress, in particular in the agonistic interactions among individuals of the same specie and in the concentration of the hormone cortisol. It was ended that the green and black colors are recommended to the maintenance of the species, for they liven up the agonistic interactions and the stress, while the brown and blue should be avoided for they stimulate these answers.
\end{abstract}

Key Words: aggressiveness, background color, behaviour, metabolism, Oreochromis niloticus, social stress

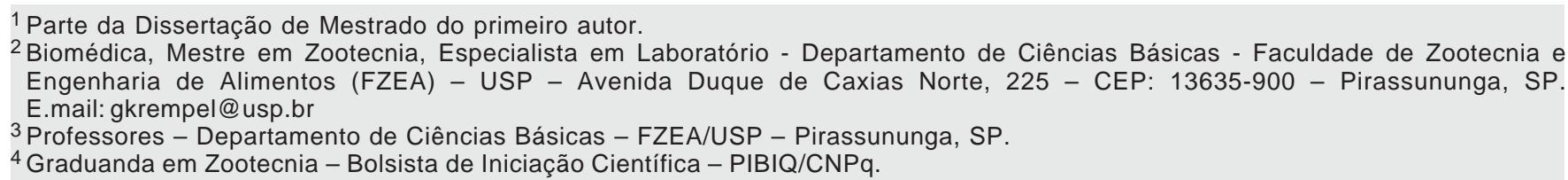




\section{Introdução}

A tilápia do Nilo, uma espécie de peixe territorialista, apresenta hierarquia de dominância e submissão estabelecida por confrontos entre os indivíduos (confrontos agonísticos), em que os animais maiores geralmente são dominantes e os menores, submissos. O estabelecimento e a manutenção desta hierarquia provoca tanto nos animais dominantes como nos submissos uma situação de estresse (estresse social), porém com maior intensidade nos animais submissos (Fernandes, 1997).

Antes mesmo que os confrontos agonísticos sejam detectados, pode ocorrer manifestação fisiológica associada ao aumento da atividade metabólica, fato sugestivo de que a visão de indivíduos da mesma espécie seja suficiente para promover essas alterações (Volpato et al., 1987).

Estudando a tilápia do Nilo, Freitas (1988) demonstrou que a visão da imagem refletida em espelho por alevinos desta espécie promove aumento no consumo de oxigênio. Wirtz \& Davenport (1976) obtiveram o mesmo resultado para a espécie Blennius pholis e sugeriram que a simples presença de um coespecífico já se constitui num estressor.

Embora os peixes tenham a capacidade natural de responder fisiologicamente, adaptando-se às alterações provocadas por um estresse moderado, Barton \& Iwana (1991) complementam que, no caso de estresse crônico, o animal perde a capacidade de adaptabilidade, torna-se mais susceptível às doenças e, em casos mais extremos, morre.

Os efeitos metabólicos do estresse social provavelmente são maiores em condições de cativeiro, pois a oportunidade para a fuga é limitada, influenciando o desempenho dos peixes na aqüicultura. Esta situação, caracterizada pela perda da homeostasia, é um fenômeno complexo que vem sendo estudado sob diferentes perspectivas, promovendo a elaboração, por vários pesquisadores, de postulados que definem este tema (Friend, 1991).

O aumento da atividade muscular e o estresse sofrido durante o transporte, a captura e o manejo dos peixes podem, inclusive, reduzir o tempo de rigor mortis e, assim, o peixe estressado pode desenvolver um rigor mais drástico, podendo afetar até a textura da carne (Nakayama et al., 1992). De fato, a carne de peixes submetidos a diferentes níveis de estresse apresenta qualidade inferior e maior susceptibilidade aos processos degradativos durante o armazenamento, comparada à carne de peixes não estressados antes do abate (Lowe et al., 1993).

A cor do ambiente é outro fator que pode desencadear aumento ou depressão de padrões comportamentais em diferentes intensidades. Em estudos realizados com tilápias do Nilo (Oreochromis niloticus), Fanta (1995) sugeriu que as cores preta, branca, amarela e vermelha devem ser evitadas, pois causam diferentes níveis de estresse ou mudanças significativas no comportamento, enquanto a verde seria indicada como a mais adequada em meios artificiais como tanques de criação ou aquários experimentais, por corresponder àquela do ambiente natural de regiões onde a espécie ocorre e não interferir significativamente em seu comportamento.

Apesar de os peixes diurnos, como Oreochromis niloticus, receberem de sua visão forte estímulo sensorial para discriminação de movimentos, formas, cores, aspecto topográfico e profundidade (Fanta et al., 1995), poucos trabalhos publicados relatam a importância da percepção do contraste sobre a alimentação de peixes.

Howell (1977), citado por Dendrinos et al. (1984), relatou crescimento mais rápido e maior sobrevivência de larvas de "turbot", Scophthalmus maximus, alimentadas com Brachionus e criadas em tanques pretos, comparativamente àquelas criadas em tanques brancos.

O efeito da cor do meio sobre a alimentação também foi relatado por Ostrowski (1989), que destaca a cor do tanque de criação como o principal fator sobre as taxas de sobrevivência de larvas de dourado marinho (Coryphaema hippurus) em cativeiro. Este autor encontrou percentagem de sobrevivência significativamente elevada para tanques pretos, comparativamente aos tanques mais claros ou brancos, recomendando o uso de tanques pretos para sistemas em que rotíferos são usados como alimento.

Green et al. (1991) relataram a influência da cor do ambiente sobre o metabolismo, demonstrando na truta arco-íris (Salmo gairdneri), que a quantidade do hormônio concentrador de melanina (MCH) liberada pelos peixes mantidos em tanques brancos foi superior àquela observada nos animais criados em tanques pretos.

Papoutsoglou et al. (2000), por intermédio da quantificação do cortisol plasmático, observaram menor grau de estresse em carpas mantidas em ambientes brancos, comparativamente aos ambientes preto e verde.

R. Bras. Zootec., v.33, n.4, p.828-837, 2004 
Os objetivos do presente trabalho foram avaliar e comparar as respostas comportamentais e fisiológicas de juvenis de tilápia do Nilo (Oreochromis niloticus), mantidos em condição de isolamento e submetidos à reflexão da própria imagem no espelho, em função da coloração do ambiente.

\section{Material e Métodos}

O presente experimento foi realizado no Laboratório Multiusuário de Ciências Ambientais da Faculdade de Zootecnia e Engenharia de Alimentos da Universidade de São Paulo, em Pirassununga (FZEA/USP).

Exemplares de tilápia do Nilo (Oreochromis niloticus) com aproximadamente $100 \mathrm{~g}$ foram aclimatados às condições laboratoriais, durante 30 dias em uma caixa de PVC com capacidade para 500 $\mathrm{L}$, dotada de filtro biológico acionado por bombas submersas $(500 \mathrm{~L} / \mathrm{h})$, à temperatura de $26 \pm 1^{\circ} \mathrm{C}$, fotoperíodo de 12 horas e receberam alimento ad libitum, duas vezes ao dia ( 9 e $17 \mathrm{~h}$ ), na forma de ração comercial extrusada.

Durante a aclimatação, os aquários de manutenção/observação foram preparados, sendo recobertos com folhas coloridas de papel-cartão, compondo cinco tratamentos (preto, verde, marrom, azul e branco) com cinco repetições cada.

Após a aclimatação, os animais foram individualmente anestesiados (solução 2-phenoxyethanol, 1:2000; Sigma, durante um minuto) e triados, selecionando-se 25 indivíduos de comprimentos e pesos semelhantes entre si.

Cada peixe, com comprimento médio de $14,70 \pm 0,17 \mathrm{~cm}$ e peso médio de 109,03 $\pm 4,45 \mathrm{~g}$, foi isolado em aquário de vidro com capacidade para $30 \mathrm{~L}$ dotado de filtro biológico acionado por micro-compressores de ar e substrato de pedrisco, à temperatura de $26,7 \pm 0,2^{\circ} \mathrm{C}$, fotoperíodo de 12 horas e recebeu alimento na proporção de $3 \%$ da biomassa, duas vezes ao dia.

Foram realizadas, durante 60 dias, sessões semanais de filmagens, com duração de 10 minutos para cada aquário, de forma a compor seis etapas distintas e alternadas: a) etapas um, três e cinco: os dados foram registrados mantendo-se os animais isolados; b) etapas dois, quatro e seis: no dia anterior à filmagem, colocou-se um espelho recoberto com papel plastificado (respectiva cor do ambiente), o qual foi removido no momento da filmagem, para que a presença de um outro peixe (intruso virtual) fosse simulada através da reflexão. Este procedimento visou habituar os peixes à presença dos espelhos, evitando a adição de um outro agente estressor no momento da observação e coleta de sangue.

Após cada sessão de filmagens, os animais foram individualmente anestesiados, para obtenção de amostras de sangue por meio de punção sangüínea na região próxima à nadadeira caudal, utilizando-se seringas de 1,0 $\mathrm{mL}$ previamente heparinizadas. As amostras obtidas foram imediatamente centrifugadas (3.000 rpm durante 15 minutos), separando-se o plasma e congelando-o $\left(-30^{\circ} \mathrm{C}\right)$ para análises posteriores das concentrações plasmáticas de glicose, triglicerídeos, proteínas totais e cortisol.

Visando a comparação entre os comportamentos observados, na condição de isolamento ou simulação da presença de um intruso virtual (imagem refletida no espelho) em ambientes de diferentes cores, foi elaborado um etograma cujos padrões são detalhados a seguir:

a) Distribuição na coluna d'água: com base nas três regiões pré-determinadas da coluna d’água, inferior, média e superior, registrou-se minuto a minuto, a distribuição espacial de cada indivíduo. A observação deste padrão comportamental objetivou estudar a ocorrência de territorialidade, bem como sua posição espacial ao longo do tempo;

b) Coloração externa do animal: registrou-se minuto a minuto, o número de listras escuras presentes em cada indivíduo, determinando se o animal permaneceu predominantemente mais claro ou mais escuro. Este padrão comportamental foi utilizado como indicador do bem-estar animal;

c) Atividade locomotora: cronometrou-se o tempo gasto em atividade locomotora para cada um dos indivíduos, durante os dez minutos de cada sessão de filmagem;

d) Confronto agonístico do tipo lateral: freqüência com que o animal ficou em posição paralela à sua imagem refletida no espelho, emitindo movimentos ondulatórios do eixo maior do corpo;

e) Confronto agonístico do tipo frontal: freqüência com que o peixe se aproximou frontalmente de sua imagem refletida no espelho e tocou-a com a boca aberta, em movimentos alternados de aproximação e afastamento;

f) Confronto agonístico do tipo ameaça: investida do animal contra sua imagem, porém sem resultar em contato com o espelho, algumas vezes acompanhada de tremores do corpo e eriçamento da nadadeira dorsal;

\section{R. Bras. Zootec., v.33, n.4, p.828-837, 2004}


g) Posição da nadadeira dorsal: registrou-se o posicionamento da nadadeira dorsal, considerando-a retraída, quando seus raios estavam dispostos longitudinalmenteem relação ao dorso do animal, ou eriçada, quando apresentavam disposição aproximadamente perpendicular em relação ao dorso; e

h) Postura do animal: caracterização da posição em que o peixe se apresentava, se reto ou inclinado, padrão também indicativo do bem-estar animal.

As concentrações plasmáticas de glicose e triglicerídeos foram obtidas por metodologia enzimática e, para quantificação de proteínas totais, executou-se o método colorimétrico. Os níveis plasmáticos do hormônio cortisol foram medidos a partir de métodos imunoenzimáticos (EIA), sendo os coeficientes de variação inter e intra ensaios de 6,1\% e $10,52 \%$, respectivamente. Estas variáveis foram analisadas no Laboratório Multiusuário de Experimentação Animal da FZEA/USP.

Concomitantemente a essas análises, avaliou-se a qualidade da água contida nos aquários, visando garantir o bem-estar dos animais e evitar a adição de mais um fator estressante. Diariamente, no período da tarde (16h), registrou-se a temperatura da água dos aquários e do ambiente. Semanalmente, registrou-se o pH e quantificaram-se as concentrações de oxigênio dissolvido, amônia e nitrito.

Efetuaram-se dois estudos para comparar as alterações ocorridas entre as variáveis comportamentais e fisiológicas. No primeiro deles, analisaram-se, separadamente, os animais na condição de isolamento e na presença de espelhos, em função dos tratamentos propostos. No segundo, analisaram-se, conjuntamente, peixes isolados e submetidos ao espelho para cada um dos tratamentos (cores).

Devido à grande variabilidade e à não-ocorrência de distribuição normal dos resultados obtidos, aplicou-se o método não-paramétrico de Kruskal-Wallis (ZAR, 1984), adotando-se $p<0,05$ como nível de significância. Para verificar a distinção entre as médias, aplicou-se o teste de Comparações Múltiplas de Dunn.

\section{Resultados e Discussão}

Os resultados obtidos para os parâmetros indicadores de qualidade de água não variaram significativamente entre os tratamentos ( $p>0,05)$. A temperatura foi mantida a $27,0 \pm 0,1^{\circ} \mathrm{C}$ e o oxigênio dissolvido, a 5,7 $\pm 0,2 \mathrm{mg} / \mathrm{L}$. A média dos valores registrados para o pH foi de 6,95 $\pm 0,05$; a amônia e o nitrito mantiveram-se em valores similares, 0,04 $\pm 0,01 \mathrm{mg} / \mathrm{L}$. Desse modo, a variabilidade das freqüências observadas nos padrões comportamentais e parâmetros fisiológicos não pode ser atribuída à estas variáveis. De acordo com Kubitza (2000), os níveis destes parâmetros encontrados estão na faixa ideal de conforto para a espécie.

A utilização de espelhos visando a simulação da presença de um coespecífico não apenas permitiu o aumento do número de repetições, mas também, como observado por Volpato et al. (1989), evitou a possível perda de animais (morte), em decorrência de injúrias conseqüentes aos intensos confrontos observados entre indivíduos da espécie.

Estudos relatam a importância da visão de cor sobre o comportamento alimentar, a sobrevivência e o desempenho de larvas de várias espécies de peixes, porém, são poucos os trabalhos enfocando possíveis alterações do comportamento de manutenção ou dos parâmetros fisiológicos destes animais frente à coloração do ambiente.

O comportamento alimentar é um dos mais importantes fatores responsáveis pelo desempenho das espécies na natureza e em tanques artificiais. Por isso, muitos autores obtiveram resultados positivos em seus trabalhos, quando utilizaram a capacidade de discriminação de cores, para melhorar a visibilidade do alimento e garantir o aumento do consumo e a sobrevivência dos peixes.

\section{Análise comportamental}

Distribuição dos peixes na coluna d'água

Observou-se que este padrão de comportamento não foi alterado pelas diferentes cores de ambiente impostas nem pelas situações sociais (isolados ou com espelhos), pois, fixando-se as regiões inferior, média e superior e comparando-as, os peixes distribuíram-se da mesma maneira em todos os tratamentos.

Entretanto, ressalta-se a preferência dos peixes pelo posicionamento na região inferior da coluna d'água em todo período experimental, sendo significativamente maior $(p=0,0079)$ em relação às regiões média e superior.

Volpato et al. (1989) descreveram relação entre a posição hierárquica e a ocupação da região da coluna d’água em tilápias da mesma espécie, sendo os indivíduos dominantes os que ocupam com maior freqüência a região inferior e os submissos, a região superior da coluna d'água. Sugere-se, então, que os

R. Bras. Zootec., v.33, n.4, p.828-837, 2004 
peixes, neste experimento, demonstraram condição de dominância por ocuparem preferencialmente a região inferior da coluna d'água no momento em que foram submetidos ao intruso virtual (imagem refletida no espelho).

Fanta (1995) relatou maior freqüência de ocupação da região inferior por indivíduos mantidos no ambiente azul e preferência pela região média, para os peixes mantidos nas demais cores de ambiente estudadas. Tais resultados diferem dos encontrados neste trabalho, já que as cores dos aquários não influenciaram o posicionamento na coluna d'água.

\section{Coloração externa dos peixes}

Os peixes permaneceram predominantemente claros durante todo o período experimental, sugerindo que as condições impostas neste experimento não afetaram seu bem-estar.

Isolando-se cada cor de ambiente e comparando-se as situações sociais, os peixes submetidos ao espelho apresentaram freqüência de coloração clara significativamente superior $(\mathrm{p}=0,0096)$ à dos peixes isolados, somente no ambiente azul. Este resultado assemelhou-se ao de Fanta (1995) que observou maior freqüência de coloração clara para tilápias mantidas no ambiente azul, em comparação às mantidas nos ambientes verde, preto, branco, amarelo e vermelho.

Volpato et al. (1989) observaram que indivíduos dominantes exibem coloração clara após confrontos agonísticos entre coespecíficos e os submissos adquirirem coloração escura. O mesmo relatou Freitas (1988), porém submetendo tilápias à própria imagem refletida em espelho. Este autor sugeriu que os indivíduos, nesta situação, claramente assumem os mesmos padrões exibidos por animais em confrontações agonísticas com coespecíficos, e até mesmo chegam a exibir padrões de dominância.

Pode-se sugerir, então, que os peixes no ambiente azul exibiram comportamento de dominância, por apresentarem, frente ao intruso virtual, maior freqüência de coloração clara. Além disso, a posse prévia do território assegura a posição hierárquica do animal (Volpato et al., 1987), como ocorreu neste estudo.

\section{Atividade locomotora}

Na condição de isolamento, não houve diferença significativa $(p>0,05)$ deste padrão para as diferentes cores. Porém, peixes submetidos ao espelho apresentaram freqüências de atividade locomotora significativamente maiores $(\mathrm{p}=0,0445)$ nos tratamentos azul e marrom (Tabela 1$)$.

\footnotetext{
R. Bras. Zootec., v.33, n.4, p.828-837, 2004
}

Na análise da condição social, os indivíduos na presença de espelho apresentaram média das freqüências de atividade locomotora significativamente maior que os isolados ( $p=0,0251 \mathrm{e} \mathrm{p}=0,0489$, respectivamente) novamente nos ambientes azul e marrom. Estes resultados assemelham-se aos obtidos por Fanta (1995), que também observou maior atividade locomotora na cor azul comparada às demais cores estudadas.

Pôde-se constatar que as cores de ambiente marrom e azul estimularam a atividade locomotora dos animais da espécie estudada quando submetidos à sua imagem refletida em espelho. Destaca-se aqui a importância da simulação de um coespecífico para aumentar a freqüência deste padrão, fato que não foi suficiente para estimular a locomoção nas demais cores de ambiente estudadas.

Freitas (1988) relatou que a presença do espelho aumentou a locomoção das tilápias, como se o espelho as estimulasse, indicando que algum fator estava presente nesta situação experimental. Porém, permaneceu a dúvida de que o aumento da atividade locomotora promovido pelo espelho tenha decorrido da visão da imagem refletida ou da percepção de profundidade que os espelhos promoviam.

Tabela 1 - Tempo de atividade locomotora de juvenis de tilápia do Nilo mantidos isolados e submetidos à reflexão da própria imagem no espelho, em função da coloração do ambiente, durante 10 minutos de observação

Table 1 - Time of motility of Nile Tilapia juvenile maintained isolated and submitted to the reflection of the own image in mirror, in function of background color, during ten minutes of observation

\begin{tabular}{|c|c|c|}
\hline \multirow{2}{*}{$\begin{array}{l}\text { Tratamento } \\
\text { Treatment }\end{array}$} & \multicolumn{2}{|c|}{$\begin{array}{c}\text { Atividade locomotora (segundos) } \\
\text { Motility (seconds) }\end{array}$} \\
\hline & $\begin{array}{l}\text { Isolado } \\
\text { Isolated }\end{array}$ & $\begin{array}{l}\text { Espelho } \\
\text { Mirror }\end{array}$ \\
\hline $\begin{array}{l}\text { Preto } \\
\text { Black }\end{array}$ & $207,93^{a}$ & $300,33^{a}$ \\
\hline $\begin{array}{l}\text { Verde } \\
\text { Green }\end{array}$ & $323,60^{a}$ & $340,87^{a}$ \\
\hline $\begin{array}{l}\text { Marrom } \\
\text { Brown }\end{array}$ & $277,53^{a}$ & $399,33^{b}$ \\
\hline $\begin{array}{l}\text { Azul } \\
\text { Blue }\end{array}$ & $290,93^{a}$ & $427,67^{\mathrm{b}}$ \\
\hline $\begin{array}{l}\text { Branco } \\
\text { White }\end{array}$ & $262,20^{\mathrm{a}}$ & $297,33^{\mathrm{a}}$ \\
\hline
\end{tabular}


Volpato et al. (1989) observaram na mesma espécie que os peixes dominantes apresentam maior freqüência de atividade locomotora que os submissos, demonstrando que a posição hierárquica também interfere neste padrão comportamental. Salienta-se que a hierarquia de dominância se estabelece imediatamente após a inclusão de outro indivíduo no ambiente estudado.

\section{Confrontos agonísticos}

As freqüências de confrontos corpóreos laterais exibidas pelos peixes mantidos no ambiente verde foram significativamente menores $(p=0,0034)$ comparadas àquelas exibidas pelos animais nos ambientes marrom, azul e branco (Figura 1). Esta diferença também foi observada entre os indivíduos do ambiente branco em relação aos do ambiente preto.

Avaliando-se os confrontos corpóreos frontais, percebeu-se que os resultados se repetiam, ou seja, os peixes dos aquários verde e preto manifestaram freqüências significativamente menores $(p=0,0349)$ em comparação àqueles dos aquários marrom, azul e branco (Figura 2).

Já para os confrontos do tipo ameaça, os peixes mantidos em aquários verdes exibiram as mesmas freqüências daqueles em aquários marrons e azuis,

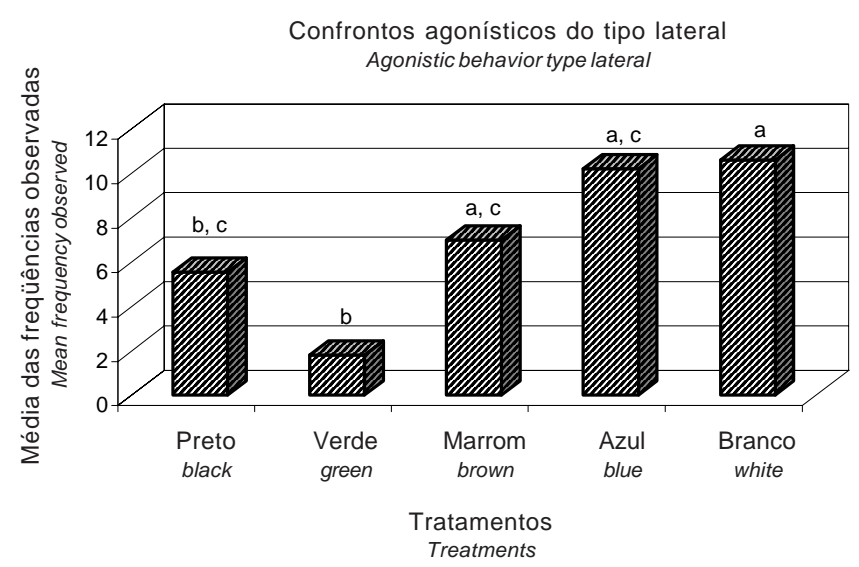

* Médias com letras distintas indicam diferença estatisticamente significativa $(p<0,05)$.

* Means with distinct letters indicate statistically significant differences $(p<.05)$.

Figura 1 - Confrontos agonísticos do tipo lateral, observados em juvenis de tilápia do Nilo submetidos à reflexão da própria imagem no espelho, em função da coloração do ambiente.

Figure 1 - Agonistic behaviours type lateral of Nile Tilapia juvenile submitted to the reflection of the own image in mirror, in function of background color. que foram significativamente superiores $(\mathrm{p}=0,0068)$ àquelas exibidas pelos indivíduos dos aquários pretos. Os peixes mantidos em ambientes azuis também se diferenciaram em relação aos dos ambientes brancos (Figura 3).

Na presença do espelho, as cores de ambiente marrom, azul e branco desencadearam maior freqüência de confrontos agonísticos do tipo lateral e frontal e apenas as cores azul e marrom estimularam as ameaças. Peixes mantidos nos ambientes preto e verde também apresentaram estes tipos de confronto, porém em menor intensidade que os demais.

Estes dados concordam com Fanta (1995) que observou maiores freqüências de comportamentos agressivos, com ataques durante parte significativa do tempo e contínua característica de alerta para os peixes que estavam no ambiente azul. Para aqueles mantidos nos ambientes brancos, registrou-se depressão na agressividade e, para os dos ambientes pretos, obtiveram-se valores ainda mais baixos.

Padrões de comportamento agonístico já haviam sido observados, em tilápias do Nilo, por Volpato et al. (1987), sendo também freqüentes em muitas outras espécies de peixe. Os confrontos agonísticos são comuns em peixes territoriais, como a tilápia, e deter-

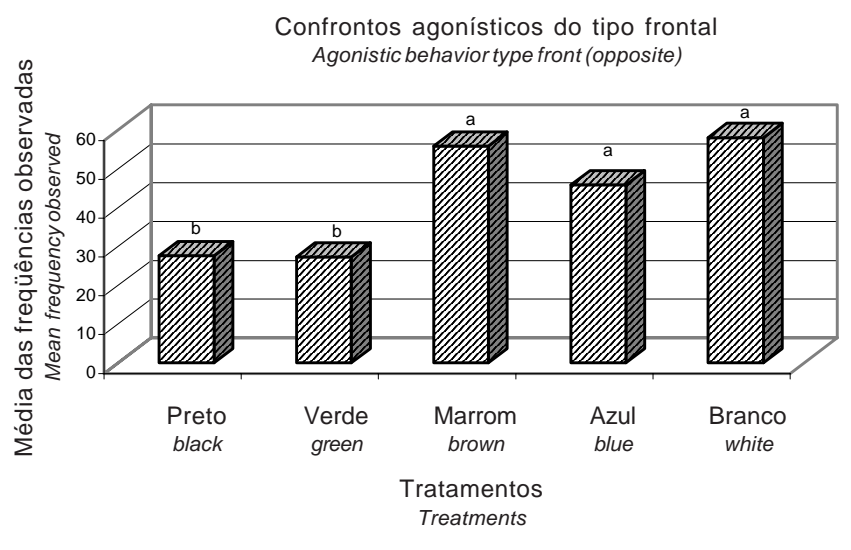

* Médias com letras distintas indicam diferença estatisticamente significativa $(p<0,05)$.

* Means with distinct letters indicate statistically significant differences $(p<.05)$.

Figura 2 - Confrontos agonísticos do tipo frontal observados em juvenis de tilápia do Nilo submetidos à reflexão da própria imagem no espelho, em função da coloração do ambiente.

Figure 2 - Agonistic behaviours type front (opposite) of Nile tilapia juvenile submitted to the reflection of the own image in mirror, in function of background color.

R. Bras. Zootec., v.33, n.4, p.828-837, 2004 
minam hierarquia de dominância entre os peixes e, por sua vez, a territorialidade.

A análise deste padrão comportamental confirmou a suposta posição de dominância, acentuada pelos demais comportamentos, dos indivíduos mantidos nos ambientes marrom e azul, pois a alta freqüência de confrontações dos peixes submetidos ao espelho sugere domínio de território.

\section{Posição da nadadeira dorsal}

Avaliando-se as cores de ambiente, notou-se que, na cor marrom, os indivíduos isolados exibiram freqüências significativamente superiores desta variável $(p=0,0002)$ comparativamente àqueles em ambientes preto e branco (Tabela 2). Animais mantidos no ambiente azul também apresentaram freqüências significativamente maiores, quando comparados aos do ambiente branco, na condição de isolamento.

Para os animais expostos ao espelho, os ambientes marrom, azul e branco se destacaram em relação aos demais, por proporcionarem freqüências significativamente maiores $(\mathrm{p}=0,0496)$.

Estudando-se as situações sociais em uma mesma cor de ambiente, os resultados mostraram claramente que, ao serem expostos ao espelho, os peixes exibiram freqüências significativamente maiores quando comparadas àquelas observadas nos animais em situação de isolamento para os ambientes preto ( $p=0,0044)$, verde $(p=0,0069)$, azul $(p=0,0379)$ e branco $(\mathrm{p}<0,0001)$. Destaca-se a expressão deste comportamento no ambiente marrom tanto para indivíduos isolados quanto para aqueles com espelho.

Ficou evidente que a imposição dos espelhos simulou a presença de um coespecífico, pois a exibição deste padrão comportamental ocorreu com maior freqüência, em todos os aquários, quando os peixes foram submetidos ao intruso virtual, com exceção para o ambiente marrom, onde os animais apresentaram-se em constante estado de alerta, independentemente da condição social.

Dados semelhantes foram encontrados por Bakker \& Sevenster (1983), em estudos utilizando Gasterosteus aculeatus, pois, durante a confrontação, notaram que a nadadeira dorsal destes animais permaneceu eriçada. Volpato et al. (1987) confirmaram este padrão comportamental para a tilápia do Nilo (Oreochromis niloticus).

Utilizando-se de espelhos, Freitas (1988) também observou na tilápia do Nilo que a disposição da nadadeira dorsal é alterada em função do grau hierárquico de dominância dos indivíduos do grupo, verificando que os animais assumiam postura semelhante àquela apresentada nos momentos de confrontações agonísticas, havendo inclusive ocorrência de padrões característicos de dominância.

Análise dos parâmetros metabólicos e hormonais Glicose, triglicerídeos e proteínas totais

Não houve diferença significativa $(p>0,05)$ para as variáveis estudadas, nem entre as cores de ambiente nem entre as situações sociais.

Os valores médios encontrados para concentração de glicose plasmática foram de $63 \mathrm{mg} / \mathrm{dL}$ para peixes isolados e $68 \mathrm{mg} / \mathrm{mL}$ para peixes submetidos ao espelho. Iwama (1997) demonstrou que os níveis de glicose podem ser empregados para avaliar a intensidade do estresse em peixes e ressaltou que, para salmonídeos, valores abaixo de $72 \mathrm{mg} / \mathrm{dL}$ são indicativos de animais sem estresse e acima de $90 \mathrm{mg} / \mathrm{dL}$ de animais em situação de estresse. Sugere-se, então, que as variáveis empregadas no presente trabalho não promoveram esta resposta nos peixes estudados.

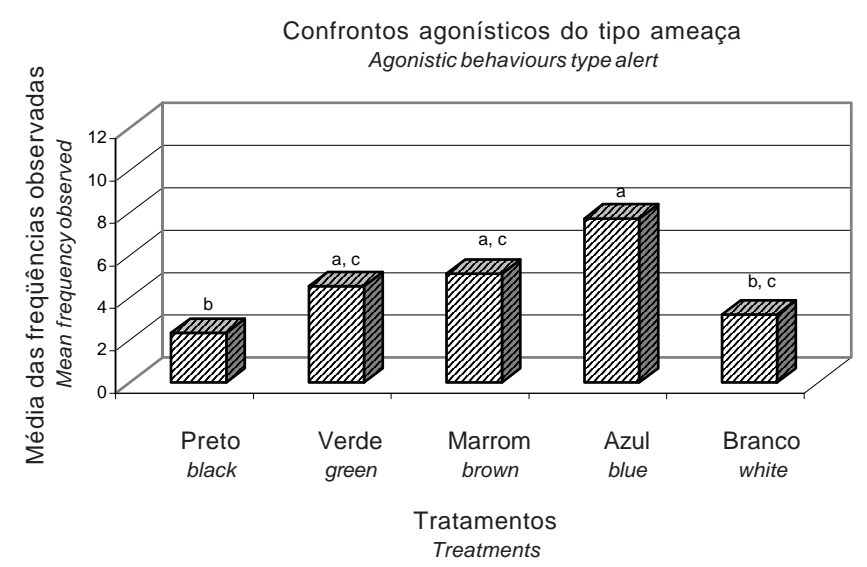

* Médias com letras distintas indicam diferença estatisticamente significativa $(p<0,05)$.

* Means with distinct letters indicate statistically significant differences $(p<.05)$.

Figura 3 - Confrontos agonísticos do tipo ameaça observados em juvenis de tilápia do Nilo submetidos à reflexão da própria imagem em espelho, em função da coloração ambiente.

Figure 3 - Agonistic behaviours type alert of Nile tilapia juvenile submitted to the reflection of the own image in mirror, in function of background color. 
A produção imediata de glicose após o estresse pode advir da glicogenólise, enquanto sua manutenção por períodos mais longos decorre da gliconeogênese de substratos, incluindo o lactato e aminoácidos (Vijayan et al. 1997). Desse modo, esta via metabólica requer maior tempo para ser ativada, podendo-se sugerir que o tempo de exposição ao agente estressor não foi suficiente para promover aumento nos níveis plasmáticos de glicose.

De fato, segundo Friend (1991), a taxa de secreção de glicocorticóides, assim como sua permanência na corrente sangüínea, é dependente da intensidade e duração do agente estressor.

Outra via metabólica de produção de energia estudada foi a concentração plasmática de triglicerídeos no plasma do animal. Segundo Peters et al. (1980) e Vijayan et al. (1991), as catecolaminas e o cortisol, por meio da ativação da lipase, facilitam a utilização de triglicerídeos, aumentando a concentração de ácidos graxos livres, sendo uma possível fonte energética em condições de aumento de demanda fisiológica em peixes submetidos ao estresse.

As situações sociais e os tratamentos impostos no presente trabalho também não promoveram alterações de triglicerídeos plasmáticos, provavelmente devido ao curto período em que os animais foram submetidos ao agente estressor, sugerindo-se que apenas um estresse mais intenso seria capaz de mobilizar triglicerídeos.

Selye (1950), Barton \& Iwama (1991) e Bonga (1997) demonstraram que a proteólise muscular é a principal causa de perda de peso, caracterizada como respostas terciárias ao estresse, sendo comum em animais submetidos cronicamente a esta condição.

Não foram encontradas diferenças quanto às concentrações de proteínas totais plasmáticas para nenhuma situação social ou tratamento, provavelmente devido ao curto período em que os animais foram submetidos ao agente estressor.

Peters et al. (1980) e Fernandes (1997) também não encontraram diferenças quanto aos níveis de proteínas totais em peixes submetidos ao estresse agudo, causado por interações agonísticas não intensas, afirmando que a mobilização de proteínas como fonte energética é dependente da intensidade do estresse a que o animal foi submetido.

\section{Cortisol}

As médias obtidas para os animais submetidos ao espelho foram significativamente distintas $(\mathrm{p}=0,0182)$

Tabela 2 - Freqüências de posição da nadadeira dorsal de juvenis de tilápia do Nilo mantidos isolados e submetidos à reflexão da própria imagem no espelho, em função da coloração do ambiente

Table 2 - Frequency of dorsal fin position of Nile Tilapia juvenile maintained isolated and submitted to the reflection of the own image in mirror, in function of background color

\begin{tabular}{|c|c|c|c|c|}
\hline \multirow{2}{*}{$\begin{array}{l}\text { Tratamento } \\
\text { Treatment }\end{array}$} & \multicolumn{2}{|c|}{$\begin{array}{c}\text { Nadadeira dorsal eriçada } \\
\text { Dorsal fin bristled }\end{array}$} & \multicolumn{2}{|c|}{$\begin{array}{c}\text { Nadadeira dorsal retraída } \\
\text { Dorsal fin retracted }\end{array}$} \\
\hline & $\begin{array}{l}\text { Isolado } \\
\text { Isolated }\end{array}$ & $\begin{array}{l}\text { Espelho } \\
\text { Mirror }\end{array}$ & $\begin{array}{l}\text { Isolado } \\
\text { Isolated }\end{array}$ & $\begin{array}{l}\text { Espelho } \\
\text { Mirror }\end{array}$ \\
\hline $\begin{array}{l}\text { Preto } \\
\text { Black }\end{array}$ & $1,00^{\text {bc A }}$ & $4,66^{\mathrm{bB}}$ & $9,00^{\text {bc A }}$ & $5,33^{\mathrm{bB}}$ \\
\hline $\begin{array}{l}\text { Verde } \\
\text { Green }\end{array}$ & $1,33^{\mathrm{abA}}$ & $4,66^{\mathrm{bB}}$ & $8,66^{\mathrm{abA}}$ & $5,4^{\mathrm{bB}}$ \\
\hline $\begin{array}{l}\text { Marrom } \\
\text { Brown }\end{array}$ & $4,06^{\mathrm{a} A}$ & $6,40^{\mathrm{a} \mathrm{A}}$ & $5,93^{\mathrm{a} A}$ & $3,6^{\mathrm{a} A}$ \\
\hline $\begin{array}{l}\text { Azul } \\
\text { Blue }\end{array}$ & $3,00^{\text {ac } A}$ & $5,7^{\text {a } \mathrm{B}}$ & $7,00^{\mathrm{ac} \mathrm{A}}$ & $4,26^{\mathrm{a} B}$ \\
\hline $\begin{array}{l}\text { Branco } \\
\text { White }\end{array}$ & $0,26^{\mathrm{bA}}$ & $6,2^{\text {a B }}$ & $9,73^{\mathrm{bA}}$ & $3,8^{\mathrm{a} \mathrm{B}}$ \\
\hline $\begin{array}{l}\text { * Médias com I } \\
\text { mente signifi } \\
\text { * Médias com } \\
\text { mente signifi } \\
\text { * Means with dis } \\
(p<.05) \text {. } \\
\text { * Means with dis }\end{array}$ & $\begin{array}{l}\text { minúscula } \\
\text { a }(p<0,05) \\
\text { maiúscul } \\
\text { a }(p<0,05) \\
\text { inuscule let } \\
\text { apital letters }\end{array}$ & $\begin{array}{l}\text { na mesm } \\
\text { na mesn } \\
\text { ame colum } \\
\text { line, indica }\end{array}$ & $\begin{array}{l}\text {, indicam d } \\
\text { indicam d } \\
\text { statistically } \\
\text { cally significa }\end{array}$ & $\begin{array}{l}\text { estatistica } \\
\text { estatistica } \\
\text { nt differences } \\
n \text { ces }(p<.05)\end{array}$ \\
\hline
\end{tabular}

R. Bras. Zootec., v.33, n.4, p.828-837, 2004 
para os ambientes marrom e azul, onde as concentrações do hormônio cortisol foram superiores comparativamente àquelas obtidas para os juvenis mantidos em ambiente preto (Tabela 3).

Comparando-se os indivíduos isolados e com espelho num mesmo tratamento verificou-se diferença significativa entre eles $(\mathrm{p}<0,05)$. Os peixes submetidos ao espelho apresentaram concentrações de cortisol significativamente superiores nos ambientes marrom ( $\mathrm{p}=0,0185)$ e azul $(\mathrm{p}=0,0115)$ quando comparadas àquelas obtidas nos animais mantidos isolados.

Foram encontrados níveis significativamente maiores de cortisol plasmático entre os peixes mantidos nos ambientes marrom e azul e que estavam submetidos à própria imagem refletida em espelho.

Iwana (1997) afirma que, em salmonídeos, animais submetidos a uma situação de estresse apresentam níveis de cortisol acima de $10 \mathrm{ng} / \mathrm{mL}$, considerando essa concentração plasmática como um limiar indicativo. Se fosse utilizado apenas o nível de cortisol como referência, poder-se-ia concluir que os

Tabela 3 - Concentração plasmática de cortisol de juvenis de tilápia do Nilo mantidos isolados e submetidos à própria imagem refletida em espelho, em função da coloração ambiente

Table 3 - Cortisol plasmatic concentration of Nile Tilapia juvenile maintained isolated and submitted to the reflection of the own image in mirror, in function of background color

\begin{tabular}{|c|c|c|}
\hline \multirow[t]{2}{*}{$\begin{array}{l}\text { Tratamento } \\
\text { Treatment }\end{array}$} & \multicolumn{2}{|c|}{$\begin{array}{l}\text { Média da concentração } \\
\text { plasmática de cortisol }(\mathrm{ng} / \mathrm{mL}) \\
\text { Mean of cortisol plasmatic } \\
\text { concentration }(\mathrm{ng} / \mathrm{mL})\end{array}$} \\
\hline & $\begin{array}{l}\text { Isolado } \\
\text { Isolated }\end{array}$ & $\begin{array}{c}\text { Espelho } \\
\text { Mirror }\end{array}$ \\
\hline $\begin{array}{l}\text { Preto } \\
\text { Black }\end{array}$ & $4,38^{\mathrm{a} A}$ & $5,18^{\mathrm{bA}}$ \\
\hline $\begin{array}{l}\text { Verde } \\
\text { Green }\end{array}$ & $5,55^{\mathrm{a} A}$ & $6,85^{\mathrm{ab} A}$ \\
\hline $\begin{array}{l}\text { Marrom } \\
\text { Brown }\end{array}$ & $5,58^{\mathrm{aA}}$ & $10,60^{\text {a } \mathrm{B}}$ \\
\hline $\begin{array}{l}\text { Azul } \\
\text { Blue }\end{array}$ & $5,36^{\mathrm{aA}}$ & $10,18^{\mathrm{a} \mathrm{B}}$ \\
\hline $\begin{array}{l}\text { Branco } \\
\text { White } \\
\end{array}$ & $5,55^{\mathrm{a} A}$ & 7,39 ab A \\
\hline $\begin{array}{l}\text { * Médias com } \\
\text { indicam difer } \\
\text { * Médias com } \\
\text { indicam difer } \\
\text { * Means with di } \\
\text { statistically sig } \\
\text { * Means with dis } \\
\text { significant diffe }\end{array}$ & $\begin{array}{l}\text { núsculas } \\
\text { tisticame } \\
\text { laiúscula } \\
\text { tisticame } \\
\text { scule lette } \\
\text { erences ( } \\
\text { letters, in } \\
\text {.05). }\end{array}$ & $\begin{array}{l}\text { mesma coluna, } \\
\text { a }(p<0,05) . \\
\text { mesma linha, } \\
\text { a }(p<0,05) . \\
\text { column, indicate } \\
\text { dicate statistically }\end{array}$ \\
\hline
\end{tabular}

animais experimentais estavam em situação de estresse nos ambientes marrom e azul (10,60 e $10,18 \mathrm{ng} / \mathrm{mL}$, respectivamente) após a adição do fator estressante (imagem refletida).

Outros resultados, realizados com truta arco-íris, Oncorhynchus mykiss, mostraram que não houve diferença significativa nos níveis de cortisol plasmático entre os animais mantidos em tanques pretos e brancos (Gilham \& Baker, 1985), concordando com aqueles obtidos neste experimento. Todavia, Papoutsoglou et al. (2000) encontraram níveis significativamente distintos para o cortisol plasmático entre ambientes pretos e brancos para a carpa prateada.

Em tilápias do Nilo (Oreochromis niloticus), o estresse social possui forte influência nas respostas fisiológicas individuais, por caracterizarem-se como animais territorialistas e bastante agressivos (Volpato et al., 1989).

Balm et al. (1994) verificaram que o pareamento de tilápias durante três horas resultou em aumento do hormônio adrenocorticotrófico (ACTH) e cortisol plasmático apenas para os animais dominantes, sugerindo que estes indivíduos apresentam respostas imediatas. Estes resultados concordam parcialmente com os obtidos neste experimento, observando-se aumento do cortisol plasmático apenas nos indivíduos mantidos nos ambientes marrom e azul, que apresentaram comportamentos típicos de animais dominantes.

Concordando com esses resultados, Overli et al. (1999) relataram que a ativação e o término da resposta ao estresse, ou seja, do sistema Hipotálamo-HipófiseInter-renal, são maiores e mais rápidos em indivíduos dominantes comparativamente aos submissos.

\section{Conclusões}

Existe influência da cor do ambiente sobre o estresse social em juvenis de tilápias do Nilo, em particular nas interações agonísticas entre coespecíficos ena concentração plasmática do hormônio cortisol. As cores verde e preta são recomendadas à manutenção da espécie, por amenizarem as interações agonísticas e o estresse, enquanto a marrom e azul devem ser evitadas por estimularem estas respostas.

\section{Literatura Citada}

BAKKER, T.H.C.M.; SEVENSTER, P. Determinants of dominance in male stickleblacs (Gasterosteus aculeatus L.). Behaviour, v.86, n.1-2, p.55-71, 1983. 
BALM, P.H.M.; PEPELS, P.; HELFRICH, S. et al. Adrenocorticotropic hormone in relation to interrenal function during stress in tilapia (Oreochromis mossambicus). General and Comparative Endocrinology, v.96, p.347-360, 1994.

BARTON, B.A.; IWANA, G.K. Physiological changes in fish from stress in aquaculture with emphasis on the response and effects of corticosteroids. Annual Review of Fish Diseases, v.10, p.03-26, 1991.

BONGA, S.E.W. The stress response in fish. Physiological Review, v.77, p.591-625, 1997.

DENDRINOS, P.; DEWAN, S.; THORPE, J.P. Improvement in the feeding efficiency of larval, post larval and juvenile dover sole (Solea solea L.) by the use of staining to improve the visibility of Artemia used as food. Aquaculture, v.38, p.137-144, 1984.

FANTA, E. Influence of background color on the behavior of the fish Oreochromis niloticus (Cichlidae). Arquivos de Biologia e Tecnologia, v.38, n.4, p.1237-1251, 1995.

FERNANDES, M.O. Estresse social, metabolismo e crescimento em peixes. Botucatu: Universidade Estadual Paulista, 1997. 82p. Tese (Doutorado) - Universidade Estadual Paulista, 1997.

FREITAS, E.F.L. Efeito da visão da imagem refletida em espelho sobre o consumo de oxigênio de alevinos de tilápia-do-Nilo (Oreochromis niloticus). Botucatu: Universidade Estadual Paulista (Monografia), 1988. 39p.

FRIEND, T.H. Symposium: Response of animals to stress: Behavioral aspects of stress. Journal of Dairy Science, v.74, p.292-303, 1991.

GILHAM, I.D.; BAKER, B.I. A black background facilitates the response to stress in teleosts. Journal of Endocrinology, v.105, p.99-105, 1985

GREEN, J.A.; BAKER, B.I.; KAWAUCHI, H. The effect of rearing rainbow trout on black or white background on their secretion of melanin-concentration hormone and their sensitivity to stress. Journal of Endocrinology, v.128, p.267-274, 1991.

IWANA, G.K. Stress in fish. Annals of the New York Academy of Science, v.851, p.304-310, 1997.

KUBITZA, F. Tilápia: tecnologia e planejamento na produção comercial. 1.ed. Jundiaí: 2000. 285p.

LOWE, T.E.; RYDER, J.M.; CARRAGHER, J.F. et al. Flesh quality in snapper, Pagrus-auratus, affected by capture stress. Journal of Food Science, v.58, n.4, p.770-773, 1993.

NAKAYAMA, T.; DA-JIA, L.; OOI, A. Tension changes of stresses and unstressed carp muscle isometric rigor contraction and resolution. Nippon Suisan Gakkaishi, v.58, p.1517-22, 1992.
OSTROWSKI, A.C. Effect of rearing tank background color on early survival of dolphin larvae. The Progressive FishCulturist, v.51, n.3, p.161-163, 1989.

OVERLI, O.; OLSEN, R.E.; LOVIK, F.; RINGO, E. Dominance hierarchies in arctic charr, Salvelinus alpinus L.: differential cortisol profiles of dominant and subordinate individuals after handling stress. Aquaculture Research, v.30, n.4, p.259-264, 1999.

PAPOUTSOGLOU, S.E.; MYLONAKIS, G.; MILIOU, H. et al. Effects of background color on growth performances and physiological responses of scaled carp (Cyprinus carpio L.) reared in a closed circulated system. Aquacultural Engineering, v.22, p.309-318, 2000.

PETERS, G.; DELVENTHAL, H.; KLINGER, H. Physiological and morfological effects of social stress in the eel (Anguilla anguilla L.). Archiv Fur Fischereiwissenschaft, v.30, n.2-3, p.157-180, 1980.

SELYE, H. Stress and the general adaptation syndrome. British Medical Journal, v.1, p.1383-1392, 1950.

VIJAYAN, M.M.; BALLANTYNE, J.S.; LEATHERLAND, J.F. Cortisol-induced changes in some aspects of the intermediary metabolism of Salvelinus fontinalis. General and Comparative Endocrinology, v.82, p.476-486, 1991.

VIJAYAN, M.M.; PEREIRA, C.; GRAU, E.G. et al. Metabolic responses associated with confinement stress in tilapia: the role of cortisol. Comparative Biochemistry and Physiology C-Pharmacology Toxicology \& Endocrinology, v.116C, n.1, p.89-95, 1997.

VOLPATO, G.L.; FRIOLI, P.M.A.; CARRIERI, M.P. et al. Comportamento de dominância e crescimento em peixes. In: COSTA, M.J.R.P.; NASCIMENTO JR., A.F. (Eds.) Anais de Etologia. Jaboticabal: 1987, v.5, p.169-194.

VOLPATO, G.L.; FRIOLI, P.M.A.; CARRIERI, M.P. Heterogeneous growth in fishes: some new data in the Nile tilapia Oreochromis niloticus and a general view about the cusal mechanisms. Boletim of Physiology Animal, v.13, p.7-22, 1989.

WIRTZ, P.; DAVENPORT, J. Increased oxygen consumption in blennies (Blennius pholis L.) exposed to their mirror images. Journal of Fish Biology, v.9, n.1, p.67-74, 1976.

ZAR, J.H. Bioestatistical analysis. 2.ed. Englewood: Englewood Cliffs Prentice-Hall, 1984. 718p.

Recebido em: 11/03/03

Aceito em: 02/10/03 